\title{
RATIO ET AUCTORITAS: ALGUNAS REFLEXIONES SOBRE LA SIGNIFICACIÓN DE LAS DECISIONES RAZONADAS
}

\section{INTRODUCCIÓN HISTÓRICA}

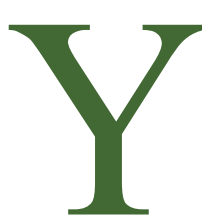

a en el siglo IV a.C. el filósofo griego Aristóteles sostuvo que la democracia política era un Estado gobernado por el Derecho. Otra característica de la democracia política es el principio de publicidad que siglos más tarde formuló Bentham de la siguiente manera: «La publicidad es la verdadera alma de la justicia» ${ }^{1}$. En consecuencia, las leyes y los procedimientos jurídicos son de interés público e incumbe al juez presentar públicamente las razones de sus decisiones. Ésta es la idea principal en la que se basa este trabajo.

El título del trabajo, Ratio et Auctoritas, alude a la oposición entre la racionalidad de las razones dadas por los tribunales y la autoridad del juez como tal. Históricamente, con la emergencia del «Rule of Law» y la aparición del «Rechtsstaat», la decisión judicial ha evolucionado claramente desde la autoridad del que toma la decisión a la importancia de la decisión razonada. El Derecho romano consideraba que la principal fuente del Derecho era la autoridad de los juristas y no las razones o fundamentos: stat pro ratione auctoritas ${ }^{2}$. Lo mismo puede decirse del Derecho canónico temprano -si cautus sit iudex, nullam causam exprimet ${ }^{3}$.

A medida que se va desarrollando el procedimiento jurídico, con constancia por escrito y la posibilidad de recurrir contra una decisión, se va haciendo sentir la necesidad de tener razones para las decisiones escritas. En la Europa continental y en los Países

${ }^{1}$ Bentham, citado en Scott v. Scott (1913), A. C 417, 477.

${ }^{2}$ F. Schultz, Roman Legal Science, Oxford, 1946, págs. 17, 61. También J. P. Dawson, The Oracles of Law, Ann Arbor, 1968, págs. 103, 108.

${ }^{3} \mathrm{Ph}$. Godding, «Jurisprudence et motivation des sentences de moyen âge à la fin de $18 \mathrm{e}$ siècle», La motivation des décisions de justice, Bruselas, 1978, pág. 48. 
Nórdicos las razones aducidas por el tribunal superior o el supremo iban destinadas solamente a los otros tribunales, manteniéndose más o menos en secreto frente a las partes implicadas y al público en general. Durante el siglo XIX, sin embargo, como consecuencia, inter alia, de la revolución francesa, los códigos de toda Europa, a excepción de Inglaterra, prescribían que los tribunales tenían la obligación de declarar las razones de su decisión. Así, la evolución que empezó en la Auctoritas, terminó, al menos en ciertos aspectos, en la Ratio.

J. P. Dawson, un historiador del Derecho americano, sostuvo la idea de que en Europa central el deber de fundamentar las decisiones judiciales tuvo una gran importancia para el estatus de los tribunales, al obligar a los jueces «a participar en una exposición razonada de reglas jurídicas y al imponerles una responsabilidad directa por las razones que se les exigía publicar» ${ }^{4}$. La historia muestra que este deber de los tribunales creció con el constitucionalismo y el parlamentarismo, fomentados por la Revolución francesa y la caída de la sociedad feudal.

\section{LA SITUACIÓN ACTUAL}

Los sistemas jurídicos de Francia, República Federal de Alemania, Inglaterra, Estados Unidos y los Países Nórdicos acentúan la obligación de dar razones para las decisiones judiciales. Aunque este requisito no se exprese en la Constitución o en las prácticas constitucionales de algunos de esos países, puede al menos derivarse implícitamente; este es el caso, por ejemplo, de la moderna Constitución alemana. Ni la práctica constitucional en Inglaterra ni la constitución federal de los Estados Unidos formulan el requisito de las decisiones razonadas en los procedimientos judiciales. Varios Estados americanos, por ejemplo California, recogen en sus constituciones el requisito de que las decisiones deben ser razonadas y escritas. Más aún, la Rule 52(a) de la Federal Rulesfor Civil Procedure estipula que los tribunales de distrito federales deben especificar las determinaciones de hecho y las conclusiones de Derecho. No hay, sin embargo, una obligación similar para los tribunales federales superiores. Por lo que se refiere a los tribunales de los estados, las prácticas varían.

En Inglaterra, el common law no requiere decisiones razonadas. Sin embargo, en diferentes tipos de casos, por ejemplo en procedimientos de familia, se exigen razones específicas.

\footnotetext{
${ }^{4}$ Dawson, op. cit., pág. 88.
} 


\section{Conclusiones en torno al estado actual de la cuestión}

El deber de formular razones para las decisiones se manifiesta hoy con algunas excepciones como un deber legalmente establecido, y también como opiniones críticas de los tribunales de revisión, seguidas a veces por la suspensión del juicio y la remisión del caso incluso cuando el Código de procedimiento en cuestión no prescribe explícitamente estas sanciones. Las bases comunes para esta práctica son en todo lugar las mismas: la utilidad de las decisiones razonadas.

De todos los ordenamientos jurídicos referidos hasta ahora, sólo el common law inglés y los tribunales de apelación federales americanos carecen de reglas que exijan formular las razones de las decisiones. Parecería que hay al menos dos fundamentos en favor de reglas explícitas. Su mera existencia prepara el terreno para que los tribunales se ajusten a su intención, es decir, la del legislador. Una regla o norma jurídica de este tipo sirve también como punto de referencia específico para el tribunal de revisión, el cual cuando critica una deficiencia en el razonamiento puede declarar que se ha violado esta regla. Por otro lado, son los propios tribunales los que en última instancia deciden el alcance de tales reglas, aunque el legislador puede atribuir a su violación una u otra consecuencia jurídica. Sin embargo, los tipos de regla aquí discutidos de vez en cuando pueden verse como una interferencia impropia con la libertad legítima y tradicional de los tribunales y, además, una regla de obligación de declarar las razones, si cubre un área amplia de diversas decisiones judiciales, debe ser necesariamente vaga. Por principio, tal regla sólo puede prescribir que la determinación de los hechos y el razonamiento jurídico del tribunal sean completos. En los fundamentos de las decisiones jurídicas forma y substancia, procedimiento formal y Derecho substantivo, se encuentran. Por lo tanto, es equivocado ver los fundamentos sólo como una cuestión de forma. La forma influye sobre la substancia, y, como ha sido correctamente dicho en un caso inglés, un defecto en la motivación es «una cuestión material de forma» ${ }^{5}$.

\section{Declaración equivocada de razones}

Al menos en el procedimiento civil una declaración de razones equivocada sólo puede llevar a que el tribunal de revisión

${ }^{5}$ Re Poyser and Mill's Arbitrarion (1964), 2 Q. B. 467, 468. 
vuelva a redactar los fundamentos con las razones correctas. Una pequeña excepción a esta regla puede verse en el Derecho francés. Cuando una parte de la motivación [opinión] de un tribunal es considerada un excès de pouvoir, la decisión puede ser declarada nula (cassée) aunque el resultado del caso pueda considerarse correcto. Esta peculiaridad del procedimiento francés, esto es, anular el fallo basado sobre ciertos argumentos inapropiados tal y como están expresados en la motivación, tiene naturalmente una explicación histórica.

\section{Omisión de razones}

En relación con el razonamiento jurídico que hay detrás de la decisión, los requisitos específicos difieren de un país a otro. Una cosa, sin embargo, tienen en común y es la necesidad de determinar de forma definitiva los hechos del caso.

\section{Procedimiento y razonamiento}

Sería una simplificación excesiva concluir simplemente que el requisito de declarar las razones tiene una posición fuerte en aquellos países donde está prescrito por el Derecho y donde la violación conduce a consecuencias en el tratamiento del caso. Aunque esto es verdad, la respuesta puede cambiar si se toma en cuenta todo el campo del Derecho procesal. Por ejemplo, una debilidad en el requisito de dar razones puede compensarse: la exigencia de dar razones puede asumir una forma y una significación diferentes mediante otras reglas de procedimiento. Por tanto, para decidir este punto, tenemos que ver los respectivos procedimientos en general.

De forma un tanto idealizada, puede decirse que los tres tipos de procedimiento aquí implicados son: la casación, la revisión y la apelación ${ }^{6}$. El significado de estos conceptos está ligado básicamente al tribunal supremo de cada sistema, donde se ven con más claridad las diferencias. En un sistema de revisión, el tribunal supremo sólo conoce cuestiones de Derecho. En un sistema de casación, sólo considera si las decisiones son conformes

${ }^{6}$ «Apelación» proviene del latín «appelare»y aquí se usa para referirse a un sistema donde los tribunales supremo o superior conocen tanto cuestiones de Derecho como de hecho. 
a Derecho, y las que no lo sean pueden ser casadas (cassés). En un sistema de apelación, por otro lado, el tribunal supremo, conoce tanto cuestiones de Derecho como de hecho. En general, mientras Alemania, Estados Unidos e Inglaterra tienen sistemas de revisión, Francia tiene la conocida Cour de Cassation. Para el procedimiento civil, los países Nórdicos, hasta cierto punto, tienen sistemas de apelación, pero siempre con algunas reglas de «certiorari».

Evidentemente, la Cour de Cassation sólo enjuicia la legalidad de la decisión, o más bien, su conformidad con las fuentes del Derecho. Para esta tarea es necesario que el tribunal inferior haya declarado tanto la norma jurídica que ha aplicado como al menos los hechos definitivos de forma suficientemente precisa. Si no lo ha hecho, el control por parte de la Cour de Cassation resultaría imposible. En casos de determinación deficiente de los hechos, la insatisfactoriedad de las razones lleva a las manque o défaut de base légale, $\mathrm{y}$ otras deficiencias pueden significar un defaut de motifs. Consecuentemente, es imposible enjuiciar un fallo a menos que éste vaya acompañado de una declaración clara de los hechos y del razonamiento jurídico, por breve que sea.

En un sistema de revisión, en el que el tribunal supremo conoce sólo cuestiones de Derecho, es a menudo difícil separar estas cuestiones de las de hecho, y en ocasiones tales tribunales tienen que enjuiciar cuestiones mixtas de Derecho y de hechos. Para poder ser juzgado, el fallo debe ir acompañado por lo menos de los hechos definitivos y de algunas alusiones al razonamiento jurídico que está detrás de la decisión. En apelación, finalmente, como mínimo, los hechos definitivos deben haber sido declarados por el tribunal inferior, naturalmente, para permitir un proceso con sentido por el alto tribunal.

El fallo mismo y las razones están en el centro del sistema de cassation. Los defectos de forma son de relevancia directa para la Cour de Cassation que, por así decir, juzga el fallo mismo incluyendo sus fundamentos. En el sistema de revisión éstos son de importancia menor, mientras que en el sistema de apelación, los hechos definitivos son de la máxima importancia, incluso si el tribunal de apelación revisa todo el caso, tanto cuestiones de Derecho como de hecho.

A pesar de las diferentes tendencias en los diferentes códigos de procedimiento, el tratamiento de las razones y de la determinación de los hechos se ajusta bien con ellos formando parte de los respectivos sistemas a los que pertenecen los códigos. Así en un sistema de cassation, las deficiencias en los fundamentos escritos obstaculizan la revisión, y en realidad el fallo mismo. Éste 
no es siempre el caso en un sistema de revisión, e incluso menos en el de apelación.

Sólo Noruega es, en cierto sentido, una excepción a esta coherencia dentro de cada uno de los diferentes sistemas procesales en cuanto al tratamiento del razonamiento y la determinación de los hechos defectuosos y/ o insuficientes. En los casos civiles, Noruega tiene un procedimiento de apelación, pero el tratamiento de las razones deficientes es en algunos aspectos similar a lo que sucede en un sistema de casación, es decir, la cuestión se resuelve por los tribunales superiores de manera semejante a Francia.

\section{OBSERVACIONES CONCLUSIVAS SOBRE \\ LA SIGNIFICACIÓN GENERAL DE LAS RAZONES PARA LAS DECISIONES JUDICIALES}

Considerándolo todo, puede sostenerse que el «Rule of Law» se profundiza por tres vías procesales:

1. El principio de audiencia (audiatur el altera pars), que en Inglaterra y América forma parte de la justicia natural y del debido proceso de Derecho;

2. razones explícitas y determinación de los hechos;

3. derecho a apelar.

Las razones explícitamente declaradas juegan un papel importante para asegurar que el tribunal ha actuado conforme al principio de audiencia y, cuando las razones son jurídicamente malas, el remedio es el derecho a apelar. En consecuencia, otros principios básicos del Derecho procesal limitan las cuestiones a juzgar por el tribunal: el principio de audiencia asegura que las partes del caso están informadas de las reglas y hechos relevantes y las razones y la determinación de los hechos del tribunal muestran a las partes qué materiales han sido considerados y porqué. Esto subraya la importancia de la obligación de declarar las razones y los hechos en el nivel práctico del procedimiento jurídico. La declaración de las razones cumple además otras funciones, y su utilidad puede explicitarse también en el nivel de la teoría del Derecho.

La declaración de las razones para la decisión tiene una función justificatoria, ya que justificación significa dar razones apropiadas para las decisiones jurídicas. Antes de tomar la deci sión las razones son guías para el juez, y después operan como 
instrumentos para la justificación y legitimación. Es desde esta perspectiva desde la que deben entenderse las funciones o el valor de los hechos determinados y de las razones dadas. Las razones y el razonamiento en la toma de decisión judicial son tanto de utilidad social como de significación para las partes en disputa.

Moralmente, las razones constituyen una justificación del poder, y que el poder puede ser usado sólo dentro de los límites de su justificación. La democracia occidental asigna una posición central al individuo. Esto se manifiesta en las constituciones de diferentes países. El individuo ha de ser tratado con respeto, y el autorespeto de una persona es un bien para la sociedad. Por lo tanto, las autoridades están obligadas a dar información completa a un individuo que se ve afectado desfavorablemente por sus decisiones. La decisión razonada es el medio de afirmar la facultad de la razón frente al poder.

Constitucionalmente, una decisión razonada ayuda a integrar el Derecho y la justicia en la sociedad y a diferenciar entre la legislación y la toma de decisiones judiciales legítimas. Esto lo realizan los tribunales que tienen que especificar por qué actúan de una determinada manera, ya que las razones dadas permiten ver si los tribunales están invadiendo las competencias del legislativo. Una democracia opera mediante una jerarquía de la toma de decisión desde el parlamento hacia abajo. Los argumentos revelan cómo los tribunales aplican la legislación y, consecuentemente, si lo que se califica como democracia de la legislación [democracy of legislation] realmente funciona. Las motivaciones de los tribunales forman parte también de la democracia de la toma de decisión judicial. Los jueces tienen que justificar su uso del poder, y la obligación de declarar las razones limita este poder.

Tanto el «Rule of Law» como la objetividad de la decisión judicial se benefician de la práctica de dar razones. La obligación de un juez de justificar su fallo usando sólo argumentos legítimos afectará en cierta medida al resultado del caso. Los jueces sostienen que ciertos resultados de casos son injustificables y que por lo tanto tienen que buscar resultados que lo sean?

${ }^{7}$ Por ejemplo, J. M. Landis, The Administrative Process, Yale, 1938, pág. 106: «Cualquier juez puede atestiguar por su propia experiencia haberse encontrado ante casos en los que ha tenido que cambiar sus conclusiones ante la incapacidad para encontrar razones satisfactorias sobre las que apoyarlas.» Cfr. E. L. Haines, «Obligation of Magistrates to Give Reasons for Judgement», Canadian Bar Journal 1:55 (1958), p g. 57, R. Traynor, «Some Open Question 
Esto puede interpretarse como una interacción entre las razones justificatorias de una decisión y su resultado. Incluso el concepto de «justicia»o, al menos, el de «Rule of Law» (Rechtssicherheit), requiere desde un punto de vista conceptual dar razones, ya que el principio de universalidad demanda que quienquiera que trate a dos personas de manera desigual debe decir porqué. Esto representa una profundización de la máxima de justicia: no basta con hacer justicia, además tiene que verse que se hace.

El análisis y la crítica se ven muy favorecidos por la declaración de las razones. Las decisiones razonadas son sometidas a la crítica y al control de la propia actividad jurisdiccional, de los medios de comunicación y del público en general y también, a través de la discusión, pueden convertirse en vehículo de cambio y de progreso.

La interpretación de las leyes se realiza mediante decisiones razonadas que pueden crear principios prácticos y excepciones motivadas desde esos principios; y la interpretación se armoniza a través de los tribunales supremos ${ }^{8}$.

La capacidad para crear nuevas reglas es impulsada por las decisiones razonadas 9 Las motivaciones pueden ser el material del cual emerja la nueva legislación.

La doctrina del precedente está subordinada, necesariamente, a las razones para las decisiones, y éstas crean precedentes al menos de cuatro formas: 1) la disponibilidad de razones inclina a otros tribunales a seguir la decisión; 2) las razones hacen que sea más fácil seguir un precedente; 3) las razones operan con la fuerza de la autoridad; 4) el razonamiento puede apoyar razones substantivas para decisiones judiciales posteriores.

Las motivaciones disidentes cumplen muchas de las funciones importantes de las motivaciones judiciales. Funcionan como instrumentos para el control y el equilibrio en el seno del tribunal, incrementando su capacidad, e impidiendo el letargo judicial ${ }^{10}$. También se ha dicho de ellas que son poderosas armas

on the Works of State Appellate Courts», 24; Chicago Law Review, 211 (1957), pág. 218, A. Ulman, A Judge Takes the Stand, New York, 1933, pág. 197, and M. Waline, «La motivation des décisions de justice», Studia in honorem G. Andredis, 1973, págs. 545 y sigs.

${ }^{8}$ D. A. Thomas, «Sentencing: ?The Case for Reasoned Decisions”», Criminal Law Review, 1963, págs. 246 y sigs.

${ }^{9}$ Dawson, op. cit., sugiere por ejemplo que el «poder de crear nuevas reglas se debía principalmente al requisito de motivaciones razonadas».

${ }^{10}$ K. Nadelman, «The Judicial Dissent: Publication v. Secrecy», 8 American Journal of Comparative Law 415 (1959), pág. 430, y J. W. Carter, «Dissenting Opinions», 4 Hastings Law Journal, 118 (1953). 
contra el error, que ayudan a delimitar el Derecho real en un determinado caso». Los casos particulares se benefician de la posibilidad del disenso porque los jueces pueden trabajar más cuidadosamente y pueden considerar mejor el peso ${ }^{11}$ de los diferentes argumentos jurídicos. El lector de una decisión con disidencia obtendrá por lo general una idea más precisa del problema en cuestión que la que obtendría de la misma decisión sin disidencia. Con respecto a las partes afectadas, la motivación razonada suministra información y la posibilidad de controlar, lo que puede resultar claramente decisivo a la hora de considerar la posibilidad de apelar.

El realismo jurídico tosco no da mucha importancia a las motivaciones jurídicas. En el peor de los casos, las considera como «corazonadas» ["hunches»] racionalizadas por parte del juez que no explican nada y que son una mera simulación, pues no dan las razones reales de la decisión. La tesis que aquí se sostiene es, sin embargo, que las razones dadas son justificatorias, guían al juez hacia el resultado y también lo justifican ${ }^{12}$. Los argumentos en favor de esto provienen tanto de la discusión jurídica como de la práctica jurídica ${ }^{13}$. También pueden tenerse en cuenta las teorías del Derecho inglesa, americana y nórdica (entre otras cosas, acerca del razonamiento en base a fines y del razonamiento en base a políticas en las decisiones judiciales) ${ }^{14}$.

${ }^{11}$ Carter, op. cit., pág. 119.

${ }^{12}$ Thomas, op cit. Cfr. A. D'Amato, Jurisprudence, A Descriptive and Normative Analysis of Law, Dordrecht/Boston/Lancaster, 1984, págs. 60 y sig.; véase también la nota 7.

${ }^{13}$ Cfr. notas 7 y 12 .

${ }^{14}$ En este contexto, se pueden mencionar algunas tesis desarrolladas por A. Peczenik, Rätten och förnuftet, 2nd ed. Stockholm, 1988, cfr. el resumen de las págs. 155 y sigs.:

1) Una motivación jurídica es racional, y en este sentido correcta, si sería aceptada unánimemente por los juristas que piensan coherentemente, esto es, apoyan sus conclusiones en un amplio conjunto de premisas ciertas, presupuestas, demostradas y/o de alguna otra manera razonables.

2) Las premisas razonables son de las siguientes clases: «ciertas», es decir, dadas por supuestas por toda la gente o al menos toda la gente normal que pertenece a la cultura en cuestión; «presupuestas», es decir, dadas por supuestas dentro de los límites de una práctica particular perteneciente a la cultura en cuestión, v. g., dentro del paradigma jurídico; «demostradas», es decir, que se siguen de un conjunto consistente de premisas ciertas y/o presupuestas; finalmente, no refutadas y en consecuencia hipotéticamente asumidas.

3) El paradigma jurídico incluye la suposición de que el razonamiento jurídico está apoyado por el Derecho válido. También contiene opiniones jurídicas fundamentales sobre la autoridad de las fuentes del Derecho y las normas sobre el razonamiento jurídico. Finalmente, incluye algunas ideas valorativas 
Los casos del common-law con decisiones discursivas han sido utilizados para presentar teorías explicativas de las funciones de las razones judiciales ${ }^{15}$. Estas teorías bien articuladas constituyen argumentos poderosos en contra de las tesis de algunos realistas jurídicos; también lo son los casos mismos. La cuestión a plantear es la siguiente: ¿por qué iban los jueces a tomarse tanto trabajo en la elaboración de sus motivaciones e incluso cambiar de opinión en cuanto al resultado como consecuencia del proceso de redactar la motivación si las razones no fueran otra cosa que sus corazonadas revestidas de ropaje judicial? Los argumentos en favor de la perspectiva justificatoria son más convincentes que los llamados argumentos realistas. Mi postura se decanta en favor de la racionalidad jurídica frente a la toma de decisión jurídica como antojo, capricho, o como una expresión de intereses políticos. Pueden hacerse las dos siguientes observaciones.

Primera, la práctica de dar razones apoya la opinión de que la legislación, los precedentes y otras fuentes constriñen no sólo las razones dadas para una decisión, es decir, su justificación, sino también los descubrimientos del juez. Aunque, como se enfatiza en la teoría de la ciencia, génesis y justificación no son lo mismo, en el razonamiento jurídico los procesos de descubrimiento y de justificación interactúan y convergen ${ }^{16}$.

Segunda, teniendo en cuenta a los valores, los principios y los fines de justicia y el «Rule of Law», al emitir un juicio sobre una decisión de un tribunal la cuestión crucial se convierte en si las razones dadas suministran o no una justificación bien fundada $\mathrm{y}$ jurídicamente válida de la decisión.

fundamentales, referidas ante todo a la certeza jurídica y a la justicia (cfr. A. Aarnio, «Paradigms in Legal Dogmatics, Towards a Theory of Change and Progress in legal Science», en A. Peczenik, L. Lindahl and B. van Roermund, eds., Theory of Legal Science, Proceedings of the Conference on Legal Theory and Philosophy of Science, Lund, Sweden, December 11-14, Dordrecht/Boston/ Lancaster/ Tokyo, 1984, págs. 25 y sigs.; A. Aarnio, The Rational and the Reasonable, Dordrecht/ Boston/ Lancaster/ Tokyo, 1987, págs. 17 y sigs.), Cfr. A. Peczenik, The Basis of Legal Justification, Lund, 1983, passim).

${ }^{15}$ Véase J. Bell, Policy Arguments in Judicial Decisions, Oxford, 1985, y J. A. G. Griffith, The Politics of the Judiciary, Londres, 1978. Ambos, Bell y Griffith, critican a los tribunales y su crítica está fundada en la lectura de motivaciones. Cfr. También N. MacCormick, Legal Reasoning and Legal Theory, Oxford, 1978, passim, y por el mismo autor. «Coherence in Legal Justification), Theory of Legal Science, (op. cit., nota 14), págs. 235 y sigs., y finalmente R. S. Summers, «Two Types of Substantive Reasons: The Core of a Theory of Common-Law Justification», 63 Cornell Law Review, 1978, passim.

${ }^{16}$ Cfr. D. Göldner, Verfassugsprinzip und Privatrechtsnorm in den Verfassungskonformen Auslegung und Rechtsbildung, Berlín, 1969, págs. 93-95, y T. Eckhoff \& N. K. Sundby, Rettssystemer, Oslo, 1976, págs. 218-220. 
En esta perspectiva la otra cuestión, es decir, cómo se generaron realmente las razones dadas y si éstas son las razones reales del juez, adquiere una importancia relativamente menor. Así, si las razones dadas están bien fundadas y son válidas no importa si son o no las razones «reales» del juez. Tampoco importa, del mismo modo, si las razones no están bien fundadas o no son legalmente válidas. En cualquier caso, las razones realmente dadas serán juzgadas por sus propios méritos.

Se desprende, pues, que el concepto de «razones legalmente válidas» es crucial. Esta conclusión puede confirmarse mediante una ejemplificación de casos. Por ejemplo, tiene sentido argumentar que una motivación discursiva, con razones y muchos detalles, mostrará si el razonamiento es válido o inválido. El énfasis, entonces, es desplazado, mediante la formulación de razones, desde las cuestiones genéticas y psicológicas a la extraordinaria importancia de la justificación racional y explícita.

(Trad. de Josep Aguiló Regla) 